\title{
Isolated congenital anonychia
}

INSERM

\section{Source}

INSERM. (1999). Orphanet: an online rare disease and orphan drug data base. Isolated congenital anonychia. ORPHA:79143

Isolated congenital anonychia is characterized by nail abnormalities ranging from onychodystrophy (dystrophic nails) to anonychia (absence of nails). Onychodystrophyanonychia has been described in at least four generations of a family with male-to-male transmission, suggesting autosomal dominant transmission. Anonychia has been described in approximately less than 20 cases; it is likely to be transmitted as an autosomal recessive trait. Total anonychia congenita, in which all the fingernails and toenails are absent, may have an autosomal dominant inheritance pattern. 